\title{
The Ethical and Social Issues of Information Technology: A Case Study
}

\author{
Ehsan Sargolzaei \\ Computer Engineering Department, Faculty of Engineering \\ University of Zabol \\ Zabol, Iran
}

\author{
Mohammad Nikbakht \\ Computer Engineering Department, Faculty of Engineering \\ University of Zabol \\ Zabol, Iran
}

\begin{abstract}
The present study is conducted among 283 students from University of Zabol to identify the harm and ethical and social issues in the field of information technology and to classify the immoral practices that students are doing in this field. First various important issues in the field of IT in the social and ethical areas are discussed. Then the cases considered as the most commonly used immoral activities, are selected for evaluation, and the participants ranked these activities according to the method presented in the questionnaire. These activities are examined and analyzed descriptively by SPSS program, reliability of the questionnaire is measured by Cronbach's alpha coefficient, Bartlett Test of Sphericity and KMO index and the validity of the results is verified using $T$-test and the results are ranked based on the first performance that happens frequently and the last performance that happens rarely or never. Finally, a set of strategies are presented for preventing ethical abuse in the field of Information Technology so that the challenges are reduced.
\end{abstract}

Keywords-Information technology; ethical and social issues; unethical practices; students

\section{INTRODUCTION}

New advances particularly in the field of information technology have brought new scientific gains to humans but it should be noted that the entry of new scientific and technological fields will always have ethical issues and limitations. One of the interesting and, of course, new topics in the field of information technology science is computer ethics or IT ethics. The study of computer ethics has long been considered by the researchers. Today, in the digital age, the society is dependent on computers in almost all its affairs, and the study of ethics in the field of computer and information technology must always be considered.

The growth and development of the Internet has made it possible to store a large number of individuals' personal data by relying on advanced information systems and the abuse of personal data and privacy violations in the field of information technology is increasing [1].

The lack of scientific integrity in educational environments that make the most use of technology is an issue that should be considered. Illegal downloading of software is common among all social classes specially the students. The use of social networks is an inseparable part of the lives of many people and the nature of students. These cases have different effects on their lifestyle, especially on their academic performance and the length of their studies [2], [3].
On the other hand, the number of unethical sites is rising every day and the conditions for access to these sites are easier than before and the mean age of people who visit these sites is reduced. Being exposed to the unethical sites also has the dangers of high-risk sexual behavior, social dilemmas and mental and psychological problems. Communicating with anonymous people and visiting them is increasing [4].

A large percentage of users are exposed to moral damages and IT abnormalities, and having a virtual identity has become a commonplace cause of many social abnormalities. The phenomenon of Internet addiction has long been considered in the developed countries as one of the consequences of the everincreasing development of the electronic communications network and has caused various harms to the individual, family and society. The excessive use of social networks can lead to addiction and is not tolerated by many physical communities. The theft of software, films, music, etc. with copyrights has become common in some societies.

Unauthorized access to the systems (hacking) is done using different and new methods and is increasing every day. Today hackers have posed the greatest challenge against IT ethics and with a widespread violation, they make numerous attempts to influence the commercial and banking accounts of individuals and try to violate individuals' privacy [1].

Many computer games are violent and stimulate aggressive antisocial behavior in addition to violent thoughts and feelings.

Today, forging digital documents such as counterfeiting digital signatures, digital images, etc. is an important topic in the field of information security and computer ethics. Online gambling (using online websites where members can participate in a variety of games without having to be present at the site, in which everything is done online from opening an account to transferring funds, withdrawals, playing games, etc.) is increasing.

Cases such as cyber bullying and communicating with anonymous individuals, visiting them, sharing the stimulating content on the Internet, and sharing personal information on the Internet have been recognized as the dangers of Internet communications in the new era [2].

All of these cases are examples of issues that affect ethics in information technology and it is necessary to rank such issues in terms of society in order to provide a better insight to provide strategies and programs in which negative measures 
are converted to the positive affairs or ethical issues in the field of information technology are observed.

The remainder of this article is organized as follows. Section 2 presents related works. In Section 3, details the significance and objectives of the study, while Section 4 outlines the methodology and the sampling collection. The data analysis and results are provided in Section 5, the discussion and the concluding remarks are given in Section 6 and finally, the future research is discussed in Section 7.

\section{RELATED WORKS}

The high use of the Internet has led to the negligence of other important parts of life, including sleep, work, and academic achievement. Users in the Internet environment can be anonymous and engage in behaviors that are inappropriate in most physical communities. On the other hand, providing fast, cheap and convenient access to the unethical sites can be considered as a disadvantage of the use of the Internet. [5]

Studies have shown that a high percentage of employees in the workplace use the Internet for non-work purposes. Meanwhile the most common non-work activities are: visiting the chat rooms, sports websites and stock investment websites [6]. Apart from all of this, computers and the Internet have the potential to violate the privacy of users by hackers [7], [8]. Research shows that 75 percent of American children are willing to share their personal data and information with other Internet users in exchange for access to services and products provided on the Internet, which can be very dangerous [4].

In 2011, a research is conducted on the impact of virtual social networks on the academic achievement of students at Birjand University of Medical Sciences in eastern Iran. The result of this study showed that there is an inverse relationship between the use of social networks and the student's mean scores which is similar to the results of other research in this field. In this study, the most time spent on social networks is over the nights [9].

A research is conducted on the use of the Internet and social isolation among Iranian students. The study found that people who use the Internet and are addicted to social networks are faced with social isolation. It has also been shown that Internet addiction is $8.3 \%$ higher among Iranian students and the students who are addicted to the Internet feel lonelier and have less confidence than normal users [10].

Mobile cameras despite their useful applications could affect the privacy of others in public places. Although mobile phones have actually changed today's lifestyle, almost all of them are equipped with high-quality digital cameras. These cameras can capture images of people without their consent, violate their privacy, be published by the Internet and become available to others [11].

A study conducted in the United States of America in 2012 among the men showed that exposure to unethical sites has led to a high-risk sexual behavior among them [12].

Many investigations are conducted on the issue of sexually transmitted content since 2009 in many countries of the world including the United States, the United Kingdom, Australia,
Canada, China and the Czech Republic. It should be noted that researches conducted in National Campaign for the Prevention of Juvenile Injuries and Pregnancies in the United States have presented significant outcomes in the prevalence of sexting among young Internet and mobile phone users [4], [13].

Aside from an easy access to these websites, animated computer games have also been developed that allow online gaming with the opposite sex; therefore, it is clear that a wide range of users, including children, can easily become addicted to the computer games while these games can have a lot of destructive effects [5].

On the other hand, computer games are often associated with adverse social phenomena such as violence and various types of addiction among the adolescents. A wide range of computer games provokes violence indirectly. Violent computer games not only stimulate violent thoughts and feelings, but also provoke aggressive and antisocial behaviors [14], [15].

\section{SIGNIFICANCE AND OBJECTIVES}

Given that ethical abuse in the field of information technology is increasing, it is necessary to analyze these cases. The roots and underlying causes of the problems should be considered in order to provide solutions to prevent them. In this study it is attempted to examine the ethics of information technology in the academic fields, identify the existing challenges, and finally provide solutions to prevent them because the author believe that if this research is conducted in an academic setting, these cases can be more precisely reviewed and it is possible to provide the proposed training and solutions in a broader manner. Then in the future works this issue will be discussed in other age groups as well as other social classes. The main goal in this research is to examine the ethical challenges in the field of information technology and provide possible solutions for the improvement of the situation based on the achieved results.

\section{METHODOLOGY}

\section{A. Measurement}

The tool for measuring variables and indicators in this research is the questionnaire. In other words, by filling out the questionnaire, people's ideas are recorded and measured. To collect field information and complete the questionnaire, the questionnaire is designed online and provided to the statistical population. All answers to each question as well as the date and time of response are saved in the Excel file. Then SPSS software is used to analyze data. In this research the descriptive and statistical analyses of the software are used and the results are assessed using the output of this software.

The questionnaire is designed so that all unethical cases can be considered in terms of student performance. Questionnaire items are divided into two parts. The first part included the items that have case options and need to be analyzed descriptively, and the second part included the items based on the Likert scale that each one addressed an index and analyzed statistically. Using the Likert scale [16], one can assign points to each of these questions and finally rank their questions and indices. The final score of the questions and indices is also 
calculated by averaging each one. Comparing this mean shows which question or index has the highest number of agreements and ranks them from highest to lowest, respectively. It should be noted that the calculation of the score and the index is only possible in the case of questions that the Likert scale has been used in the response options and for other questions the descriptive statistics are applied.

Responses are based on 5-point Likert scale. Each respondent was requested to indicate his/her stance on each ethical statement as 1 (strongly agree), 2 (agree), 3 (not sure/undecided), 4 (disagree) or 5 (strongly disagree).

Now, with this valuation method it is possible to calculate the indices obtained by the combination of several questions by means of averaging the results. For example, to calculate the Violent Computer Games Index, which includes the items 36 and 37 , it is enough to compute the mean value of the answers to these two questions to get the index number. Table 1 presents the challenges presented in this study with items related to these issues (first part items - descriptive) and Table 2 presents the second part items including the items based on the Likert scale.

TABLE I. ETHICAL ISSUES, NUMBER OF STATEMENTS AND QUESTIONS USED IN THIS SURVEY (FIRST PART ITEMS - DESCRIPTIVE)

\begin{tabular}{|l|l|l|}
\hline Ethical issues & Number of questions & Questions \\
\hline Computer addiction & 2 & 1,2 \\
\hline $\begin{array}{l}\text { Addiction to social } \\
\text { networks }\end{array}$ & 4 & $3,4,5,6$ \\
\hline Addiction to unethical sites & 3 & $7,8,9$ \\
\hline Violent computer games & 2 & 10,11 \\
\hline
\end{tabular}

TABLE II. ETHICAL ISSUES, NUMBER OF STATEMENTS AND QUESTIONS USED IN THIS SURVEY (SECOND PART ITEMS - THE ITEMS BASED ON THE LIKERT SCALE)

\begin{tabular}{|l|l|l|}
\hline Ethical issues & $\begin{array}{l}\text { Number } \\
\text { of } \\
\text { questions }\end{array}$ & Questions \\
\hline Privacy violation & 6 & $\begin{array}{l}12,13,14,15, \\
16,25\end{array}$ \\
\hline $\begin{array}{l}\text { Negative behavioral and } \\
\text { personality impacts }\end{array}$ & 3 & $17,18,26$ \\
\hline $\begin{array}{l}\text { Formation and promotion of } \\
\text { gossip and fake news }\end{array}$ & 2 & 19,21 \\
\hline $\begin{array}{l}\text { Anti-religious propaganda (in } \\
\text { cyberspace) }\end{array}$ & 1 & 20 \\
\hline Addiction to social networks & 2 & 22,23 \\
\hline Verbal attacks & 2 & 24,27 \\
\hline $\begin{array}{l}\text { Violation of ethical principles } \\
\text { using a mobile phone camera }\end{array}$ & 2 & 25,35 \\
\hline Online theft & 4 & $28,29,30,31$ \\
\hline Hacking & 2 & 31,34 \\
\hline Copyright violation & 2 & 32,33 \\
\hline Forging digital documents & 1 & 33 \\
\hline Violent computer games & 2 & 36,37 \\
\hline Online gambling & 1 & 38 \\
\hline
\end{tabular}

\section{B. Sampling and Data Collection}

The statistical population of this study includes 283 students including 147 male and 136 female undergraduate, postgraduate and $\mathrm{PhD}$ students in University of Zabol. Students' participation in answering the questionnaire is done voluntarily and completely anonymous. It is also emphasized that participants' information will be used solely for research and research purposes and will be completely confidential.

\section{DATA ANALYSIS AND RESUlT}

\section{A. Methods of Analysis}

Reliability is one of the technical features of the measurement tools. The concept of reliability is that the measurement tools give the same results under the same conditions. Different methods are used to calculate the reliability coefficient of the measurement tools including Cronbach's Alpha method [17]. This method is used to calculate the internal coordination of the measurement tools such as questionnaires or tests that measure different characteristics. In such tools, the answer to each question can receive different numeric values. The zero value of this coefficient indicates unreliability and +1 denotes complete reliability. The reliability of the questionnaire is evaluated using Cronbach's alpha coefficient. The Cronbach's alpha value of the research questionnaire is 0.731 which indicates the desirable reliability of this questionnaire.

There are several methods for assessing the validity of the questionnaire. That Bartlett Test of Sphericity [18] and $\mathrm{KMO}^{1}$ index [19] are used. Bartlett's test examines the hypothesis that the observed correlation matrix belongs to a population with unmatched variables. Also, the KMO index is a method that takes a value between zero and one and the closer value of which to one indicates the higher detailed correlations between the variables (questionnaire items) and the higher validity. Table 3 presents the Bartlett Test of Sphericity and KMO index results.

In the present study, Bartlett Test of Sphericity is significant at a significance level of 0.05 because significance $\mathrm{P}<0.05$ and also the KMO value is acceptable. Therefore, the questionnaire has construct validity.

\section{B. Demographic and Professional Profiles}

Frequency table of respondents' educational level is presented in Table 4.

TABLE III. KMO AND BARTLETT'S TEST

\begin{tabular}{|l|l|}
\hline $\begin{array}{l}\text { Kaiser - Meyer- Olkin Measures of Sampling } \\
\text { Adequacy }\end{array}$ & $\mathbf{0 . 6 2 1}$ \\
\hline Bartlett's Test of Sphericity & \\
\hline Approx. chi- square & 1002.9 \\
\hline Significance & 0.001 \\
\hline
\end{tabular}

\footnotetext{
${ }^{1}$ Kaiser-Meyer-Olkin
} 
TABLE IV. FREQUENCY TABLE OF RESPONDENTS' EDUCATIONAL LEVEL

\begin{tabular}{|l|l|l|}
\hline & Number & Percent \\
\hline PhD & 35 & $12 \%$ \\
\hline Master's degree & 29 & $10 \%$ \\
\hline Bachelor's degree & 209 & $74 \%$ \\
\hline Associate's degree & 8 & $3 \%$ \\
\hline NA & 2 & $1 \%$ \\
\hline sum & 283 & $100 \%$ \\
\hline
\end{tabular}

As it can be observed undergraduate students form a significant portion of the statistical population. Also, most students entered the university in 2012 and 2015 . 52\% of the statistical population is the male and $48 \%$ is female that the difference in the number of male and female respondents is not significant.

\section{Analysis of Achieved Results}

Since the size of the statistical society is large enough (more than 30), the use of parametric tests such as $\mathrm{T}$ is an optional example. Therefore, in this study, T-test [20] was used to check the accuracy of the results. In Tables 5 and 6, the first (first part items - descriptive) and second (questions containing the Likert scale) part items are presented along with the corresponding indices.

The main items are the ones that have options based on Likert scale. Each of these questions will also examine a specific index. Given that the options of these questions include Likert scale, one can assign a specific point to each of these questions according to the answers and, finally, the items and their indices are ranked. In this section, the statistical description of the answers provided to each question is discussed. Table 6 summarizes the results regarding the first objective of the study, namely to addresses the respondents' attitudes towards ethical IT issues, also known as ethical orientation.

In this section, the mean score is calculated among the main items with Likert scale and it is indicated from the highest to the lowest value in the table below. The items with higher score are the one that have been more agreed than others; thus the first questions are the immoral actions with the highest frequency and the last questions are the immoral actions with the lowest frequency. Ranking the main questions of the questionnaire is listed in Table 7.

TABLE V. ETHICAL ORIENTATIONS OF RESPONDENTS TO ETHICAL ISSUES IN IT (QUESTIONS IN THE FIRST PART OF THE QUESTIONNAIRE)

\begin{tabular}{|l|l|l|l|}
\hline & The purpose of the Questions & & The obtained result \\
\hline 1 & $\begin{array}{l}\text { The rate of using a computer and checking addiction } \\
\text { to it }\end{array}$ & $15 \%$ & No computer addiction \\
\hline 2 & The reason for using a computer & $48 \%$ & Addiction to the computer for entertainment and recreation \\
\hline 3 & The rate of using virtual social networks & $65 \%$ & Addiction to virtual social networks \\
\hline 4 & $\begin{array}{l}\text { The most common reason for using the virtual social } \\
\text { networks }\end{array}$ & $3 \%$ & $\begin{array}{l}\text { Interaction with friends and relatives, and no connection with } \\
\text { strangers and finding new friends }\end{array}$ \\
\hline 5 & Membership period in the virtual social networks & $67 \%$ & Before entering university \\
\hline 6 & Times of using the virtual social networks & $74 \%$ & Night \\
\hline 7 & $\begin{array}{l}\text { Access to unethical sites through virtual social } \\
\text { networks }\end{array}$ & $37 \%$ & Significant access \\
\hline 8 & $\begin{array}{l}\text { Investigating access to unethical sites over the } \\
\text { Internet }\end{array}$ & $40 \%$ & Significant access \\
\hline 9 & The rate of use of obscene images and videos & $8 \%$ & No addiction to unethical sites \\
\hline 10 & $\begin{array}{l}\text { Checking the amount of computer games used and } \\
\text { addiction to them }\end{array}$ & $42 \%$ & No addiction to computer games \\
\hline 11 & Favorite style for computer game & $48 \%$ & Arcades and sports games \\
\hline
\end{tabular}

TABLE VI. ETHICAL ORIENTATIONS OF RESPONDENTS TO ETHICAL ISSUES IN IT (QUESTIONS IN THE SECOND PART OF THE QUESTIONNAIRE- INCLUDE LIKERT SCALE)

\begin{tabular}{|l|l|l|l|l|l|l|l|l|l|}
\hline No & Questions & Mean & SD & SA & A & I & D & SDi & NA \\
\hline 1 & By communicating with strangers in cyberspace and visiting them... & 2.54 & 1.06 & 4 & 10 & 45 & 19 & 22 & 0 \\
\hline 2 & By sharing personal information on the Internet or virtual social networks... & 2.26 & 1.14 & 4 & 11 & 22 & 32 & 31 & 0 \\
\hline 3 & I allow people with unknown true identity to access my information. & 1.73 & 0.99 & 3 & 4 & 9 & 30 & 54 & 0 \\
\hline 4 & Many profiles on social networks are fake and compromise my privacy & 3.65 & 1.13 & 25 & 37 & 25 & 7 & 7 & 0 \\
\hline 5 & $\begin{array}{l}\text { I check pictures and personal information of others without knowing whether they are ok } \\
\text { with that or not }\end{array}$ & 2.59 & 1.09 & 4 & 18 & 30 & 31 & 17 & 0 \\
\hline 6 & I share many topics that I am not interested in the real world & 2.48 & 1.08 & 3 & 14 & 33 & 28 & 22 & 1 \\
\hline 7 & Social networks have led to social isolation in me & 2.63 & 1.17 & 8 & 17 & 21 & 38 & 26 & 0 \\
\hline 8 & Most of the cyberspace shared content is unrealistic & 3.49 & 0.93 & 12 & 43 & 30 & 14 & 2 & 0 \\
\hline 9 & Anti-religious propaganda is very common in cyberspace & 3.57 & 1.05 & 18 & 41 & 25 & 13 & 4 & 0 \\
\hline 10 & I have shared the news in cyberspace that I am not sure whether they are real or rumor & 2.11 & 1.08 & 3 & 11 & 15 & 38 & 34 & 0 \\
\hline 11 & Social networks and the Internet have led to lack of academic progress in me & 2.79 & 1.22 & 9 & 23 & 20 & 32 & 15 & 0 \\
\hline 12 & $\begin{array}{l}\text { Social networks and the Internet have led me to neglect other important parts of life, } \\
\text { including sleep, work, and so on }\end{array}$ & 3.05 & 1.20 & 10 & 35 & 16 & 30 & 10 \\
\hline 13 & With verbal attacks in cyberspace... & 0 & 1.79 & 0.93 & 1 & 5 & 14 & 33 & 48 \\
\hline
\end{tabular}




\begin{tabular}{|l|l|l|l|l|l|l|l|l|l|}
\hline 14 & My friends' consent is not necessary in sharing their photos with me in cyberspace & 1.87 & 0.97 & 3 & 4 & 14 & 37 & 43 & 0 \\
\hline 15 & I feel lonely in cyberspace and have lower confidence & 2.31 & 1.08 & 4 & 10 & 26 & 34 & 26 & 1 \\
\hline 16 & On the Internet I can express my opinions freely and without any fear & 3.47 & 1.03 & 16 & 35 & 31 & 14 & 3 & 0 \\
\hline 17 & I am not willing to pay for the software, movies, music, etc., with copy rights & 3.22 & 1.18 & 18 & 23 & 28 & 25 & 6 & 0 \\
\hline 18 & I download software, movies, music, etc., with copy rights that are presented for free & 3.76 & 1.04 & 25 & 42 & 23 & 5 & 5 & 0 \\
\hline 19 & $\begin{array}{l}\text { I have software, movies, music, etc., with copy rights I have paid for but I will share them } \\
\text { with other for free }\end{array}$ & 3.62 & 0.96 & 16 & 47 & 23 & 12 & 2 & 0 \\
\hline 20 & $\begin{array}{l}\text { If needed, I would be willing to pay and enter my bank account information from the bank } \\
\text { portals about the authenticity of which I am not sure }\end{array}$ & 2.15 & 1.08 & 3 & 10 & 16 & 38 & 32 & 1 \\
\hline 21 & I am more inclined to get free articles than similar articles that are offered on a paid site & 3.66 & 1.05 & 22 & 38 & 25 & 9 & 4 & 2 \\
\hline 22 & $\begin{array}{l}\text { I use the research work or artwork of another person without mentioning the source and } \\
\text { reference }\end{array}$ & 2.48 & 1.20 & 6 & 16 & 20 & 32 & 23 & 2 \\
\hline 23 & $\begin{array}{l}\text { If necessary, I would like to use decoding software to retrieve the information resources of } \\
\text { others }\end{array}$ & 2.09 & 1.12 & 3 & 10 & 17 & 32 & 37 & 1 \\
\hline 24 & I use my mobile camera in any public place & 2.90 & 1.24 & 11 & 21 & 30 & 21 & 16 & 1 \\
\hline 25 & Violent computer games are more appealing to me & 2.73 & 1.32 & 9 & 23 & 22 & 19 & 25 & 2 \\
\hline 26 & Violent computer games provoke violent thoughts, feelings and antisocial behaviors in me & 2.77 & 1.28 & 11 & 17 & 28 & 22 & 20 & 2 \\
\hline 27 & I make money through computer games and online gambling & 2.41 & 1.21 & 5 & 15 & 25 & 23 & 30 & 2 \\
\hline Mean of all statements: 2.74 & & & \\
\hline SD: Standard deviation, SA: Strongly agree (\%), A: Agree (\%), I: Indifferent (\%), D: Disagree (\%), SDi: strongly disg. (\%) & \\
\hline
\end{tabular}

TABLE VII. RANKING THE MAIN QUESTIONS OF THE QUESTIONNAIRE

\begin{tabular}{|c|c|c|}
\hline No & Questions & Mean \\
\hline 1 & I download software, movies, music, etc., with copy rights that are presented for free. & 3.76 \\
\hline 2 & I am more inclined to get free articles than similar articles that are offered on a paid site. & 3.66 \\
\hline 3 & Many profiles on social networks are fake and compromise my privacy. & 3.65 \\
\hline 4 & I have software, movies, music, etc., with copy rights I have paid for but I will share them with other for free. & 3.62 \\
\hline 5 & Anti-religious propaganda is very common in cyberspace. & 3.57 \\
\hline 6 & Most of the cyberspace shared content is unrealistic. & 3.49 \\
\hline 7 & On the Internet I can express my opinions freely and without any fear. & 3.47 \\
\hline 8 & I am not willing to pay for the software, movies, music, etc., with copy rights. & 3.22 \\
\hline 9 & Social networks and the Internet have led me to neglect other important parts of life, including sleep, work, and so on. & 3.05 \\
\hline 10 & I use my mobile camera in any public place. & 2.90 \\
\hline 11 & Social networks and the Internet have led to lack of academic progress in me. & 2.79 \\
\hline 12 & Violent computer games provoke violent thoughts, feelings and antisocial behaviors in me. & 2.77 \\
\hline 13 & Violent computer games are more appealing to me. & 2.73 \\
\hline 14 & Social networks have led to social isolation in me. & 2.63 \\
\hline 15 & I check pictures and personal information of others without knowing whether they are ok with that or not. & 2.59 \\
\hline 16 & By communicating with strangers in cyberspace and visiting them... & 2.54 \\
\hline 17 & I share many topics that I am not interested in the real world. & 2.48 \\
\hline 18 & I use the research work or artwork of another person without mentioning the source and reference. & 2.48 \\
\hline 19 & I make money through computer games and online gambling. & 2.41 \\
\hline 20 & I feel lonely in cyberspace and have lower confidence. & 2.31 \\
\hline 21 & By sharing personal information on the Internet or virtual social networks... & 2.26 \\
\hline 22 & $\begin{array}{l}\text { If needed, I would be willing to pay and enter my bank account information from the bank portals about the authenticity of which I am not } \\
\text { sure. }\end{array}$ & 2.15 \\
\hline 23 & I have shared the news in cyberspace that I am not sure whether they are real or rumor. & 2.11 \\
\hline 24 & If necessary, I would like to use decoding software to retrieve the information resources of others. & 2.09 \\
\hline 25 & My friends' consent is not necessary in sharing their photos with me in cyberspace. & 1.87 \\
\hline 26 & With verbal attacks in cyberspace... & 1.79 \\
\hline 27 & I allow people with unknown true identity to access my information. & 1.73 \\
\hline
\end{tabular}

\section{Checking the Achieved Results by using a Single-Sample T Test}

In order to evaluate the results the mean score assigned to each index is examined and using a single-sample $\mathrm{T}$ test, the difference between the mean score and the value of 3 (the mean value of the answers of each question) is measured. In Table 8, the analysis of each index is presented. 
TABLE VIII. T TEST RESULTS FOR THE ETHICAL IsSUES’ INDICES IN THE FIELD OF INFORMATION TeChNOLOGY ETHICS

\begin{tabular}{|c|c|c|c|c|c|c|}
\hline Index & Mean & SD & D & Statistics T & significance $\mathbf{P}$ & CI \\
\hline violation of privacy & 2.44 & 0.50 & -0.56 & -15.065 & 0.001 & 2.37 to 2.51 \\
\hline negative behavioral and personality effects & 2.48 & 0.80 & -0.52 & -8.844 & 0.001 & 2.36 to 2.59 \\
\hline rapid formation and spread of rumors and false news & 2.80 & 0.69 & -0.20 & -3.873 & 0.001 & 2.70 to 2.90 \\
\hline Anti-religious propaganda in the cyberspace & 3.57 & 1.05 & -0.57 & 7.354 & 0.001 & 3.42 to 3.72 \\
\hline addiction to social networks & 2.92 & 1.08 & -0.08 & -0.994 & 0.332 & 2.76 to 3.08 \\
\hline verbal attacks & 2.63 & 0.67 & -0.47 & -7.418 & 0.001 & 2.53 to 2.73 \\
\hline online theft & 3.19 & 0.57 & -0.19 & 4.435 & 0.001 & 3.11 to 3.28 \\
\hline Hacking & 2.13 & 0.80 & -0.87 & -14.872 & 0.001 & 2.01 to 2.24 \\
\hline Copyright violation & 3.05 & 0.92 & -0.05 & 0.725 & 0.469 & 2.92 to 3.18 \\
\hline forging digital documents & 2.44 & 1.23 & -0.56 & -6.132 & 0.001 & 2.26 to 2.62 \\
\hline ethical abuse of the camera & 2.38 & 0.80 & -0.52 & 8.943 & 0.001 & 3.41 to 3.64 \\
\hline interest in violent computer games & 2.71 & 0.99 & -0.29 & -4.009 & 0.001 & 2.56 to 2.85 \\
\hline online gambling & 2.41 & 2.41 & -0.59 & -6.511 & 0.001 & 2.23 to 2.59 \\
\hline
\end{tabular}

For the privacy violation index, the mean value of the scores is 2.44 , which is 0.56 units less than the value of 3 , and the significance of the t-test at the $95 \%$ confidence level (Significance $\mathrm{P}<0.05$ ) indicates that the mean response of the individuals to the privacy violation component has a significant difference with the value of 3 and according to the $95 \%$ confidence interval, the mean response rate in the community with a $95 \%$ probability is within the range of $2.37-2.51$. Since the questionnaire options are defined so that the responses indicating the violation of the privacy of others tend to the large numbers (greater than 3 ) it is concluded that the violation of privacy is low among the students of University of Zabol because firstly, the mean response of individuals is less than 3 (to the "completely opposite" or non-violation of privacy), and secondly, the mean value is significant compared to the number 3 (Significance $\mathrm{P}<0.05$ ).

Similar to the abovementioned analysis and the data in Table 3, the results in other indicators were obtained as follows:

- The level of negative behavioral and personality effects of information technology is low among University of Zabol students.

- The rate of rapid formation and spread of rumors and false news in students of University of Zabol is lower than the mean level.

- According to the students' opinion of the University of Zabol, the level of Anti-religious propaganda in the cyberspace is very common and is at a high level.

- The amount of verbal attacks among the students at University of Zabol is lower than the mean level.

- The rate of online theft in students in University of Zabol is higher than the mean level.

- The interest in hacking is low among University of Zabol students.

- The amount of forging digital documents is low among University of Zabol students.
- The degree of ethical abuse of the camera is low among University of Zabol students.

- The level of interest in violent computer games is lower than average among University of Zabol students.

- Interest in online gambling is low among University of Zabol students.

For the addiction to social networks index, the mean value of the scores is 2.92 , which is 0.08 units less than the value of 3 , and the insignificance of the t-test at the $95 \%$ confidence level (Significance $\mathrm{P} \geq 0.05$ ) indicates that the mean response of the individuals to the privacy violation component has not a significant difference with the value of 3 and according to the 95\% confidence interval, the mean response rate in the community with a $95 \%$ probability is within the range of 2.76 3.08. it is concluded that The degree of addiction to social networks is average among University of Zabol students because according to the above test the mean value is not significant in comparison with the number 3 (Significance $\mathrm{P} \geq$ $0.05)$.

- The degree of Copyright violation is average among University of Zabol students.

\section{E. Ranking the Ethical and Social Issues Indices in the Field of Information Technology}

In the previous sections, the rate of each index was studied among students of University of Zabol. Here the Friedman test [21] is applied to rank these indices. In Table 9, the test result is presented.

Considering that the Significance $\mathrm{P}$ is less than 0.05 , the above hypothesis is rejected at the significance level of 0.05 which means that the rate of ethical and social issues indices in the field of information technology is different among University of Zabol students. Table 10 shows the mean values of each factor, according to which "anti-religious propaganda is very common in cyberspace in the view of students from the University of Zabol. Also hacking has the lowest rate among University of Zabol students. 
TABLE IX. FrIEDMAN TEST FOR RANKING THE ETHICAL AND SOCIAL ISSUES INDICES IN THE FIELD OF INFORMATION TECHNOLOGY

\begin{tabular}{|l|l|l|}
\hline Hypothesis & Test statistics & Significance P \\
\hline $\begin{array}{l}\text { The rate of ethical and social issues indices in the field of information technology is the same } \\
\text { among University of Zabol students }\end{array}$ & 400.05 & 0.001 \\
\hline
\end{tabular}

TABLE X. THE RANKING THE ETHICAL AND Social ISSUES INDICES IN THE FIELD OF INFORMATION TeChNOLOGY

\begin{tabular}{|l|l|l|}
\hline rank & Ethical and social issues indices in the field of information technology & Ave. ranking \\
\hline 1 & Anti-religious propaganda in the cyberspace & 9.96 \\
\hline 2 & Online theft & 9.28 \\
\hline 3 & Copyright violation & 8.73 \\
\hline 4 & Addiction to social networks & 7.78 \\
\hline 5 & Rapid formation and spread of rumors and false news & 7.58 \\
\hline 6 & Interest in violent computer games & 7.24 \\
\hline 7 & Verbal attacks & 6.79 \\
\hline 8 & Online gambling & 6.08 \\
\hline 9 & Negative behavioral and personality effects & 5.97 \\
\hline 10 & Forging digital documents & 5.81 \\
\hline 11 & Ethical abuse of the camera & 5.75 \\
\hline 12 & Violation of privacy & 5.67 \\
\hline 13 & Hacking & 4.35 \\
\hline
\end{tabular}

\section{DISCUSSION}

According to the conducted studies and the results obtained from this study, it can be concluded that ethics in information technology can be trained to influence the individuals. Given that there is no mandatory syllabus for students in bachelors and master and $\mathrm{PhD}$ course in Iran on ethical issues in information technology, such a program seems essential to cope with the ethical challenges of IT. Previous investigations also prove this claim [22]-[24].

In some cases, gender has a significant impact on the ethics of information technology, which can be due to local traditions, beliefs and cultural factors in Islamic countries. From a traditional and cultural point of view, women are expected to have different values than men; therefore, they have different moral behavior compared to men in different conditions. As reported in [25] and [26], women are expected to follow cultural and family values and obey tough constraints.

In terms of intellectual property, the results showed that the policies of Internet Service Providers (ISPs) and, in general, the Internet and domestic policies in some countries, such as Iran, are different than other countries. In Iran, strict software policies are not enforced, and individuals can download software and related items freely, while these policies are strict in some countries and people cannot access these data easily. Also the effective codes of ethics as well as correct policies should also be considered. In this section, the research results are consistent with other researchers' findings [27]-[31].

Two points of view can be considered for copyrights; the first point is that copyrights are incentives for creative production. The second point is that copyright is considered as a commodity for the consumer, who seeks to use it for free or at a negligible cost. Using this argument, it can be concluded that developed countries are struggling to secure the first view to have the copyright of their own works; on the other hand, in developing countries there is an attempt to reach a second view to have access to the copyright easier and at a lower cost. As the results of this study suggest, the copyright in Iran is not to be respected as well, and individuals have free access to software and some other copyrighted works free of charge. This challenge also requires growth, education and cultural developments. Also, the infrastructures ness to be corrected and punishments should be considered for the violation of copyright.

There are no significant differences regarding privacy issues at different points as well as gender which indicate that privacy is a concern for all individuals. The results of this study also confirm this issue. Of course, the study also shows that female students are more concerned about their privacy. IT professionals or computer and IT students, considering that they have more information on this subject, are more likely to respect privacy-related issues, which also refers to the training of individuals. In order to discuss the privacy of access to data, IT strategies, infrastructures and platform must be properly defined and implemented. Previous studies confirmed the results of this research in this regard [32], [33].

In this section a set of strategies and training for controlling unethical activities in the field of information technology are presented at the University of Zabol. It is hoped that considering the mentioned solutions in the previous section and these strategies and trainings the ethical and social issues will be respected in the field of information technology and their challenges are reduced.

- Addiction to social networks, cyberspace and computers:

- To create real and effective recreation and entertainment instead of virtual entertainments for students.

- To reduce addiction to social networks, cyberspace and computers at night, the false policies of some companies should be eliminated. For example the lower cost of the Internet at night should be eliminated by these companies and instead of free download at 
night, this feature is provided during the day at a lower cost rather than the night.

- Family control and monitoring can also be an effective factor in this regard.

- Addiction to online unethical sites:

- The most important and effective way to reduce addiction to unethical sites is to educate people about the dangers of addiction to it. If people become aware of the consequences and risks of being exposed to online unethical sites, the likelihood of such addiction is reduced significantly.

- There are conditions for non-access to such websites. In Iran, the filtering rule is an example of such conditions which is unfortunately not very successful.

- Addiction to violent computer games:

- Creating recreational activities, such as creating diverse sports halls, green spaces and parks, etc., is an appropriate solution to fill the students' leisure time or their lack of access to such games.

- Cultural development on the use of such games so that the hours spent on the computer games is limited.

- Localization of computer games, which means the production and presentation of domestic computer games rather than the supply of games by the other countries. This solution can be effective due to the match between the computer games and the culture and beliefs of the country of residence.

- Secularization, anti-religious propaganda and blasphemy:

- Informing people and teaching religious issues

- Confronting superstitions

- More monitoring and regulation and adopting stricter rules

- Verbal attacks:

- Non-imposition of beliefs: If people impose their opinions on a person in the real world, with respect to freedom of speech the oppressed person may fight with these beliefs as verbal attacks.

- Lack of bias: Excessive bias may cause abnormalities among people in cyberspace. Individuals in cyberspace must also respect each other's ideas and avoid bias in their thoughts. "Whoever disagrees with your thoughts is not your enemy!"

- Online theft and Copyright violation:

- Establishing state-specific rules: Unfortunately, in Iran, copyrights are not respected as they should. In this regard, the government must enforce strict rules and even take heavy fines from offenders.

- Crimes shall be considered for sources that allow illegal downloading or other online thefts.

- Cultural development; the necessary trainings are needed to raise the level of community culture in this field.

- Negative behavioral and personality impacts:
- Families' education and attention: Families' education and attention to their children from childhood play an important role in reducing the negative effects of behavior and personality.

In general, it is recommended to promote awareness of ICT ethics among students and individuals. To achieve this, a moral framework must be created and developed. In addition, in order to promote ethics, universities, as well as schools, must actively develop ethical education in their curriculum to increase ethical awareness among students as the future representatives in the IT market.

\section{CONCLUSION}

In this study the ethical and social issues in the field of information technology is evaluated. Ethical issues in the field of information technology are ranked by the results of statistical analyses. According to the students' opinion, antireligious propaganda had the highest prevalence in cyberspace among the indices that With Informing people, teaching religious issues, more monitoring and determine the correct rules it can be reduced. Also hacking was also ranked in the last place. According to the conducted studies and the results obtained from this study, it can be concluded that ethics in information technology can be trained. Therefore, mandatory syllabus for students in bachelors and master and $\mathrm{PhD}$ course on ethical issues in information technology seems essential to cope with the ethical challenges of IT. Finally, a set of strategies and training for controlling unethical activities in the field of information technology was presented with the hope that their challenges are reduced.

\section{VII.FUTURE RESEARCH}

As noted earlier, this study has studied public awareness of some ethical issues in information technology among students, but the age related issues have not been addressed. Further research can consider on cultural differences, the gender based conditions, intellectual property rights and also user privacy behaviors in social network.

\section{REFERENCES}

[1] Reynolds G, (2011) Ethics in information technology. Cengage learning.

[2] Thompson LA, Dawson K, Ferdig R, Black EW, Boyer J, Coutts J, Black NP (2008) The intersection of online social networking with medical professionalism. Journal of general internal medicine 23(7): 954-957.

[3] Kirschner PA, Karpinski AC (2010) Facebook® and academic performance. Computers in human behavior 26(6): 1237-1245.

[4] Kopecký K, Szotkowski R, Krejčí V (2012) The risks of Internet communication 3. Procedia-Social and Behavioral Sciences 69: 13481357.

[5] Korkeila J, Kaarlas S, Jääskeläinen M, Vahlberg T, Taiminen T (2010) Attached to the web-harmful use of the Internet and its correlates. European Psychiatry 25(4): 236-241.

[6] Pontell HN, Rosoff SM (2009) White-collar delinquency. Crime, Law and Social Change 51(1): 147-162.

[7] Akbulut Y, Şendağ S, Birinci G, Kılıçer K, Şahin MC, Odabaşı HF (2008) Exploring the types and reasons of Internet-triggered academic dishonesty among Turkish undergraduate students: Development of Internet-Triggered Academic Dishonesty Scale (ITADS). Computers \& Education 51(1): 463-473.

[8] Akbulut Y, Uysal Ö, Odabasi HF, Kuzu A (2008) Influence of gender, program of study and PC experience on unethical computer using 
behaviors of Turkish undergraduate students. Computers \& Education 51(2): 485-492

[9] Bijari B, Javadinia SA, Erfanian M, Abedini M, Abassi A (2013) The impact of virtual social networks on students' academic achievement in Birjand University of Medical Sciences in East Iran. Procedia-Social and Behavioral Sciences 83: 103-106.

[10] Fallahi V (2011) Effects of ICT on the youth: A study about the relationship between internet usage and social isolation among Iranian students. Procedia-Social and Behavioral Sciences 15: 394-398.

[11] Baase S (2003). A gift of fire. Social, Legal, and Ethical Issues in Computing. Prenctice-Hall.

[12] Wright PJ, Randall AK (2012) Internet pornography exposure and risky sexual behavior among adult males in the United States. Computers in Human Behavior 28(4): 1410-1416.

[13] Wolak J, Finkelhor D, Mitchell KJ (2012) How often are teens arrested for sexting? Data from a national sample of police cases. Pediatrics 129(1): 4-12.

[14] Nespor K, Csemy L (2007) Health Risks of Computer Games and Videogames. CESKA A SLOVENSKA PSYCHIATRIE 103(5): 246.

[15] Coeckelbergh M (2007) Violent computer games, empathy, and cosmopolitanism. Ethics and Information Technology 9(3): 219-231.

[16] Hedayatpanah A (2011) Fuzzy approach to Likert Spectrum in Classified levels in Surveying researches. Journal of Mathematics and Computer Science 2(2): 394-401.

[17] Santos JRA (1999) Cronbach's alpha: A tool for assessing the reliability of scales. Journal of extension 37(2): 1-5.

[18] Tobias S, Carlson JE (1969) Brief report: Bartlett's test of sphericity and chance findings in factor analysis. Multivariate Behavioral Research 4(3): 375-377.

[19] Pal Y (1986) A Theoretical study of Some Factor Analysis Problems and Pal, Y. and Bagai, OP (1987). A Common Factor Better Reliability Approach to Determine the Number.

[20] Boneau CA (1960) The effects of violations of assumptions underlying the $t$ test. Psychological bulletin 57(1): 49.
[21] Zimmerman DW, Zumbo BD (1993) Relative power of the Wilcoxon test, the Friedman test, and repeated-measures ANOVA on ranks. The Journal of Experimental Education 62(1): 75-86.

[22] Peterson DK (2002) Deviant workplace behavior and the organization's ethical climate. Journal of business and psychology 17(1): 47-61.

[23] Phau I, Kea G (2007) Attitudes of university students toward business ethics: a cross-national investigation of Australia, Singapore and Hong Kong. Journal of Business Ethics 72(1): 61-75.

[24] Kum-Lung C, Teck-Chai L (2010) Attitude towards business ethics: examining the influence of religiosity, gender and education levels. International Journal of Marketing Studies 2(1): 225.

[25] Sidani Y (2005) Women, work, and Islam in Arab societies. Women in Management Review 20(7): 498-512.

[26] Sidani Y, Zbib I, Rawwas M, Moussawer T (2009) Gender, age, and ethical sensitivity: the case of Lebanese workers. Gender in Management: An International Journal 24(3): 211-227.

[27] Mertha A (2005) The politics of piracy: Intellectual property in contemporary China. Cornell University Press.

[28] Stein L, Sinha N (2002). New global media and communication policy: the role of the state in the twenty-first century. Handbook of new media: Social shaping and consequences of ICTs 410-31.

[29] Spinello RA, Tavani HT (2005) Intellectual Property Rights: From Theory to. Intellectual property rights in a networked world: Theory and practice, 1.

[30] Kimppa K (2005) Intellectual Property Rights in Software-Justifiable from a Liberalist Position?. Intellectual property rights in a networked world: Theory and practice, 67.

[31] Stahl BC (2005) The impact of open source development on the social construction of intellectual property. Free/open source software development 259-272.

[32] Wood G (2000) A cross cultural comparison of the contents of codes of ethics: USA, Canada and Australia. Journal of Business Ethics 25(4): 287-298.

[33] Prior M, Rogerson S, Fairweather B (2002) The ethical attitudes of information systems professionals: outcomes of an initial survey. Telematics and Informatics 19(1): 21-36. 